\title{
Serum neurofilament light protein correlates with unfavorable clinical outcomes in hospitalized patients with COVID-19
}

\author{
Mercedes Prudencio ${ }^{1,2,}$, Young Erben ${ }^{3^{*}}$, Christopher P. Marquez ${ }^{4}$, Karen R. Jansen-West ${ }^{1}$, Camila Franco- \\ Mesa $^{3}$, Michael G. Heckman ${ }^{5}$, Launia J. White ${ }^{5}$, Judith A. Dunmore', Casey N. Cook ${ }^{1,2}$, Meredith T. Lilley ${ }^{1}$, \\ Yuping Song' ${ }^{1}$, Caroline F. Harlow ${ }^{4}$, Björn Oskarsson ${ }^{6}$, Katharine A. Nicholson ${ }^{7}$ Zbigniew K. Wszolek ${ }^{6}$, LaTonya \\ J. Hickson ${ }^{8}$, John C. O’Horo' ${ }^{9,10}$, Jonathan B. Hoyne ${ }^{4}$, Tania F. Gendron ${ }^{1,2}$, James F. Meschia ${ }^{6,+}$, Leonard \\ Petrucelli ${ }^{1,2, \dagger}$ \\ ${ }^{1}$ Department of Neuroscience, Mayo Clinic, Jacksonville, FL, 32224, U.S.A. ${ }^{2}$ Neuroscience Graduate Program, Mayo Clinic Graduate School of Biomedical Sciences, \\ Jacksonville, FL, 32224, U.S.A. ${ }^{3}$ Division of Vascular and Endovascular Surgery, Mayo Clinic, Jacksonville, FL, 32224, U.S.A. ${ }^{4}$ Department of Laboratory Medicine and \\ Pathology, Mayo Clinic, Jacksonville, FL, 32224, U.S.A. ${ }^{5}$ Division of Biomedical Statistics and Informatics, Mayo Clinic, Jacksonville, FL, 32224, U.S.A. ${ }^{6}$ Department of \\ Neurology, Mayo Clinic, Jacksonville, FL, 32224, U.S.A. ${ }^{7}$ Sean M. Healey \& AMG Center for ALS, Massachusetts General Hospital (MGH), Boston, MA, 02114, U.S.A. ${ }^{8}$ Division \\ of Nephrology and Hypertension, Mayo Clinic, Jacksonville, FL, 32224, U.S.A. ${ }^{9}$ Division of Infectious Diseases, Mayo Clinic, Rochester, MN, 55905, U.S.A. ${ }^{10}$ Division of \\ Pulmonary and Critical Care Medicine, Mayo Clinic, Rochester, MN, 55905, U.S.A. \\ *These authors contributed equally to this work. \\ *Corresponding author. Email: Meschia.James@mayo.edu; Petrucelli.Leonard@mayo.edu
}

Brain imaging studies of patients with COVID-19 show evidence of macro- and micro-hemorrhagic lesions, multifocal white matter hyperintensities, and lesions consistent with posterior reversible leukoencephalopathy. Imaging studies, however, are subject to selection bias and prospective studies are challenging to scale. Here, we evaluated whether serum neurofilament light chain (NFL), a neuroaxonal injury marker, could predict the extent of neuronal damage in a cohort of 142 hospitalized patients with COVID-19. NFL was elevated in the serum of patients with COVID-19 compared to healthy controls, including those without overt neurological manifestations. Higher NFL serum concentrations were associated with worse clinical outcomes. In one hundred hospitalized patients with COVID-19 treated with remdesivir, a trend toward lower NFL serum concentrations was observed. These data suggest that patients with COVID-19 may experience neuroaxonal injury and may be at risk for long-term neurological sequelae. Neuroaxonal injury should be considered as an outcome in acute pharmacotherapeutic trials for COVID-19.

\section{INTRODUCTION}

Since the World Health Organization declared a global pandemic on March $11^{\text {th }} 2020$, severe acute respiratory syndrome coronavirus 2 (SARS-CoV-2) has caused over 2.8 million deaths worldwide and more than 550,000 deaths within the United States (1). Although common symptoms of coronavirus disease 2019 (COVID-19) include fever, cough, fatigue and shortness of breath, the manifestations of COVID-19 can vary widely. For example, some patients can develop pneumonia, acute respiratory distress syndrome, myocardial injury, arrhythmias and/or multi-organ failure (2), and it is increasingly recognized that SARS-CoV-2 can cause neurologic signs (3-10). Indeed, clinical studies observed neuropsychiatric manifestations in up to $70 \%$ of patients with COVID19 , including young adults and patients in whom respiratory symptoms have long resolved (10-12). Brain imaging studies detected diverse lesions including perfusion abnormalities with or without acute infarctions, cerebral venous thrombosis, macro- and micro-hemorrhages, multifocal white matter and basal ganglia lesions, meningeal enhancement, central pontine myelinolysis, posterior reversible encephalopathy syndrome and neuritis (13-16). Moreover, brain autopsy studies found SARS-CoV-2 RNA or proteins in various neuroanatomical regions of patients with COVID-19, with astrogliosis, activation of microglia and infiltration of cytotoxic T lymphocytes noted in many cases $(17,18)$.

Given that neurologic manifestations are now considered common features of COVID-19, we sought to examine the utility of serum neurofilament light chain (NFL) in assessing the frequency, severity and clinical consequences of neuronal injury associated with SARS-CoV-2 infections warranting hospitalization. Recently, we determined that blood NFL 
concentrations are associated with radiographic markers of brain tissue damage, as well as indicators of neurological, functional and cognitive status in patients with ischemic or hemorrhagic stroke (19). Based on these findings and others (20) establishing NFL as a marker of axonal injury, we investigated whether serum NFL was elevated in hospitalized patients with COVID-19, and whether it correlated with clinical outcomes and disease severity.

\section{RESULTS}

\section{Serum neurofilament light chain (NFL) is elevated in hospitalized patients with COVID-19}

We measured NFL in 488 serum samples longitudinally collected from 142 hospitalized patients with COVID-19, and in cross-sectional serum samples from 55 healthy controls. A summary of patient demographics, treatments and clinical outcomes is shown in Table 1. Characteristics of control individuals are presented in table S1. The median age in patients with COVID-19 was 62 years (range: 22 - 99 years) and $57.7 \%$ were male ( 82 patients). In control individuals, the median age was 62 years (range: 32 - 84 years) and $50.9 \%$ were male (28 patients). Comparing mean NFL concentrations for each of the 142 patients with COVID-19 to NFL concentrations of the 55 controls revealed that serum NFL was significantly higher in patients (median $29.4 \mathrm{pg} / \mathrm{ml}$, range: 3.4 $1,538.4 \mathrm{pg} / \mathrm{ml}$ ) than controls (median $10.9 \mathrm{pg} / \mathrm{ml}$, range: 3.2 $43.2 \mathrm{pg} / \mathrm{ml} ; \mathrm{P}<0.001$; Fig. 1A). This finding was consistent after correcting for age and sex, and when examining the first, last, minimum or maximum NFL measurement per patient (Table 2). To assess how many patients with COVID-19 had elevated NFL according to a pre-specified cut-off, we determined the number of patients with an NFL concentration of at least 3 standard deviations above the group mean NFL concentration of control individuals. For this analysis, we focused on maximum NFL measurements given that NFL concentrations fluctuate between time points, as demonstrated for 35 of the patients with longitudinal NFL data (Fig. 1B), such that using mean NFL concentrations could mask our ability to discern elevated NFL concentrations at one or more time-points. Remarkably, $\sim 34 \%$ of patients with COVID-19 (48 individuals) had NFL concentrations higher than the cut-off. We additionally determined the number of patients with an NFL concentration of at least 2 standard deviations above the mean control concentration and found that $53 \%$ of patients (76 individuals) met this criterion.

\section{Elevated serum NFL associates with worse clinical out- comes in hospitalized patients with COVID-19}

We next examined the relationship between serum NFL concentrations and diverse clinical outcomes: mechanical ventilation (intubation), admission to the intensive care unit (ICU), length of hospital stay (LOS) and modified Rankin Scale (mRS) at discharge. As shown in Table 3, in unadjusted analyses and in analyses adjusting for age, sex, BMI and chronic kidney disease (CKD), serum NFL concentrations were significantly higher in patients who needed mechanical ventilation, who were admitted to the ICU, who had a longer LOS, and who had a higher mRS at discharge (all $\mathrm{P}<0.001$ ). Further, we found a positive correlation between NFL and time from admission to final blood draw (Spearman's r: 0.50, $\mathrm{P}<0.001$ ); thus, we also performed similar analyses adjusting for time from admission to final blood draw (table S2), and observed results consistent with findings reported in Table 3.

\section{Longitudinal serum NFL concentrations in hospitalized patients with COVID-19 and their association with treatment type}

Among the 142 patients with COVID-19, longitudinal NFL data were available for 100 individuals for whom serum NFL was measured for up to 17 time points. As anticipated, temporal changes in NFL differed among patients, and this was true of the 35 patients with longitudinal NFL measures and for whom mean NFL concentrations were considered elevated (Fig. 1C). For instance, in some individuals, serum NFL rose over time, whereas for others NFL remained relatively consistent or fluctuated to varying degrees.

Since patients were administered a range of potential therapies including monoclonal antibody treatment, remdesivir, dexamethasone and convalescent plasma therapy (Table 1), we next examined whether these treatments influenced NFL. Comparisons of serum NFL according to specific treatments for COVID-19 are displayed in Table 4. After adjusting for age, sex, BMI and time from admission to blood draw, as well as correcting for multiple analyses $(\mathrm{P}<0.0063$ considered as significant), a tendency toward lower serum NFL in patients who received remdesivir was observed in multivariable analysis (final NFL concentration per patient, $\mathrm{P}=0.008$; Table 4).

\section{DISCUSSION}

COVID-19 is associated with diverse neurological injuries but questions regarding their incidence, severity and longterm consequences, and whether such injuries can be mitigated by acute intervention, remain unanswered $(21,22)$. Toward addressing these important questions, we examined the utility of serum NFL in determining the frequency, severity and clinical consequences of neuronal injury in hospitalized patients with COVID-19. We show that serum NFL is elevated in patients with COVID-19, and that $\sim 34 \%$ of patients have mean NFL concentrations of at least 3 standard deviations above the group mean of control individuals. Also of note, elevated serum NFL correlates with worse clinical outcomes, such as the need for mechanical ventilation (intubation), ICU admission, longer lengths of hospitalization and worse functional outcomes. We further observed a tendency of lower 
serum NFL in patients with COVID-19 treated with remdesivir. In aggregate, these findings suggest that a considerable proportion of hospitalized patients with COVID-19 suffer neuronal injury, the degree of which associates with disease severity.

We reported that patients with COVID-19 can develop a myriad of neurologic symptoms including headaches, encephalopathy and seizures (13) providing indication for head imaging. Nevertheless, the great majority of patients with COVID-19 (86.7\%) show no intracranial abnormalities by imaging (13). It also bears mentioning that retrospective studies using brain imaging approaches in patients with COVID-19 suffer from selection bias, in particular omitting patients with mild or no obvious neurological symptoms and patients too unstable or having contraindications to undergo magnetic resonance imaging. This selection bias, combined with the uncertainty of the sensitivity of brain imaging to neuroaxonal injury (12), suggest that neuronal injury or neurodegeneration in patients with COVID-19 may be underappreciated based on imaging studies alone. Given findings from the present study, we believe that measuring serum NFL in patients with COVID-19 will facilitate the detection of neuronal injury that may otherwise be overlooked.

Our findings that serum NFL is elevated in our cohort of 142 patients hospitalized with COVID-19, and that higher serum NFL associates with worse clinical outcomes, are in line with prior reports. For example, one study observed elevated serum NFL in 28 patients with mild-to-moderate COVID-19 (23), whereas another found that, among 47 patients with COVID-19, plasma NFL was higher in the 18 patients with severe disease (24). Yet another reported serum NFL to be elevated in 29 critically ill patients with COVID-19 and to positively associate with an unfavorable outcome (25). Finally, CSF NFL was elevated in two of six hospitalized patients with moderate or severe COVID-19 (26). Our data are also congruent with the growing consensus that SARS-CoV-2 causes potentially damaging neurological problems. However, how this occurs remains unclear. Similarly to other respiratory viruses that have neuroinvasive capacities $(27,28)$, SARS-CoV-2 can spread to the central nervous system $(17,18)$. Postulated pathways by which this occurs include its retrograde axonal transport along the sensory and olfactory nerves in the cribriform plate; its invasion of endothelial cells by interacting with the angiotensin-converting enzyme 2 receptor; and its ability to alter tight junction proteins formed by endothelial cells (29). Nevertheless, despite the ability of SARSCoV-2 to invade the brain, the neurological signs and symptoms it causes are believed to more likely result from systemic reactions such as hypoxemia, hypercoagulability, systemic inflammation and multiorgan failure $(18,26,30)$.

Therapies available for COVID-19 include dexamethasone (31), monoclonal antibody toward the spike protein of SARS-
CoV-2 (32), remdesivir, a viral replication inhibitor $(33,34)$ and convalescent plasma $(35,36)$. In our cohort of patients with COVID-19, a tendency of lower serum NFL concentrations was seen with the use of remdesivir compared to its non-use. Although this association needs to be confirmed in larger patient cohorts and independently replicated, these findings underscore the utility of incorporating subacute measurements of NFL during hospitalization and in randomized drug trials.

Strengths of our study include the relatively substantial number of patients with COVID-19, the longitudinal examination of serum NFL, and our analysis of associations of NFL with clinical outcomes and treatment type. Our study also has limitations. Most patients in our cohort were hospitalized for a considerable length of time, such that data for patients with shorter hospital stays (due to less severe disease) were comparatively limited. There were also delays from time of suspected infection or the time of first symptoms to blood draw. Our analyses utilized the time of hospital admission as the baseline time point; however, the length of time from symptom onset to admission likely varies among patients. Finally, our analyses assessing associations of COVID-19 treatments with serum NFL should be viewed as exploratory. The small sample sizes together with differences in timing of treatment in relation to symptom onset, in severity of symptoms once treatment was initiated, and in duration of treatment from its initiation to blood draw for NFL measurements may have hampered our efforts to detect associations of interest. To rigorously address this question would require a randomized trial in which NFL concentrations are longitudinally measured in patients before and after treatment.

Overall, we show that serum NFL was elevated in hospitalized patients with COVID-19 and correlated with worse clinical outcomes. These data further cement the field's recognition of the neurological manifestations caused by SARS-CoV-2 infection. Nevertheless, our understanding of the long-term implications is limited. It has been shown that patients previously hospitalized with COVID-19 display a wide array of neurological symptoms months after discharge $(10,12,37)$ but few studies have systematically followed patients over time, likely because of the inherent difficulties in doing so. However, based on our present data, we posit that longitudinal measurements of serum NFL would provide an efficient means to identify and quantify neurological injury in hospitalized patients with COVID-19. Serum NFL may also be useful for monitoring end-stage organ disease progression and recovery, aiding in the identification of risk factors and clinical features that contribute to COVID-19-associated neurological signs, and indicating neuroaxonal injury in COVID19 drug trials. 


\section{MATERIALS AND METHODS}

\section{Study design}

The goal of this study was to investigate serum NFL as a biomarker of neuroaxonal injury in patients with COVID-19. NFL was measured using the NF-Light digital immunoassay from Quanterix. Our primary analyses were to determine whether serum NFL is elevated in hospitalized patients with COVID-19, and whether NFL associates with clinical outcomes and treatment type. We included 142 patients with COVID-19 (no randomization) for whom serum (488 samples) was collected cross-sectionally or longitudinally during hospitalization. Our study also included serum from 55 healthy controls. NFL was measured in a blinded manner. Sample sizes were based on what was available when the study was initiated and not on sample size calculations. Biological samples were obtained when residual blood was available from patients with approval by the ethics committee.

\section{Study subjects}

A total of 488 serum samples from 142 patients hospitalized with COVID-19 were included in this study. The Mayo Clinic Neurological, Vascular and Neurovascular Events With SARS-CoV-2 Study (MC NEWS; Institutional Review Board (IRB) \#20-003457) was queried to identify a cohort of individuals with COVID-19. MC NEWS included patients across the three major campuses of Mayo Clinic and the Mayo Clinic Health System, with hospitals in Arizona, Florida, Minnesota and Wisconsin. Fifty-five healthy controls without COVID-19 and no neurological condition were additionally included. This group was composed of 22 healthy individuals from the general population, 19 healthy spouses or caregivers of patients with ataxia $(\mathrm{N}=15)$ or amyotrophic lateral sclerosis (ALS, $N=4$ ), and 14 unaffected relatives of patients with ataxia $(\mathrm{N}=4)$ or ALS $(\mathrm{N}=10)$ and who lacked disease-associated gene mutations. Serum samples were obtained under IRB approval through the protocols: "Investigating biomarkers, disease mechanisms and treatments for spinocerebellar ataxia and nucleotide repeat diseases", IRB\#17-006033; "Investigating the Genetic and Phenotypic Presentation of Spinocerebellar Ataxia and Nucleotide Repeat Diseases", IRB\#16-009414; “Biospecimen Biorepository for the Study of ALS, ALS-FTD and Similar Neurodegenerative Disorders", IRB\#13-004314; "Pilot Evaluation of Neurofilament Heavy Form (NF-H) as a Potential Biomarker of Axonal Loss in Amyotrophic Lateral Sclerosis (ALS)", IRB\#10-003592; "Clinical \& Genetic Studies in ALS, Suspected ALS, and Other Neurodegenerative Motor Neuron Disorders", IRB\#07-005711; "Biospecimen Collection to Investigate the Causes of ALS", IRB\# 15-001187; "The DIALS (Dominant Inherited ALS) Network", IRB\# 2017P000485; and "COVID-19 cytokine storm project", IRB\#20-003661. For patients with COVID-19, the following demographic and clinical information was abstracted using the shared electronic medical record (Epic): age, sex, body mass index (BMI), chronic kidney disease (CKD) status, and COVID-19 treatment status for monoclonal antibody therapy, remdesivir, dexamethasone and convalescent plasma. The following patient outcomes were collected: need for mechanical ventilation (intubation), intensive care unit (ICU) admission, length of hospital stay (LOS), modified Rankin scale (mRS) at discharge, vital status on follow-up and death. The $\mathrm{mRS}$ is a seven-level ordered categorical scale commonly used in stroke studies that ranges from 0 (fully independent; no symptom) to 6 (death) (38). Death (not restricted to hospitalization) was summarized descriptively but was not analyzed as an outcome in association analyses owing to the small number of patients who died (13 of 142) and because death is included in the mRS at discharge outcome (note: 2 of the 13 patients who died did so after discharge. As such, only 11 patients had an mRS score of 6 at discharge). Age, race and sex were collected for the control individuals.

\section{NFL measurements}

Serum NFL concentrations were measured in duplicate in a blinded-fashion on the Simoa HD-X analyzer using the NFLight digital immunoassay (Quanterix, Cat \#103186) according to the manufacturer's instructions. Briefly, samples were thawed and cleared by centrifugation at $10,000 \times \mathrm{g}$ for $5 \mathrm{~min}$, transferred to 96 -well plates, and run in duplicate using a $4 \mathrm{X}$ instrument dilution. Four samples were included in each run to monitor potential variability among assays, along with appropriate calibrators and controls provided by the manufacturer. NFL concentrations were interpolated from the calibration curve using a 1/y2 weighted 4-parameter logistic curve fit. Samples with NFL concentrations that exceeded the range of the assay were retested using an appropriate atbench dilution in addition to the $4 \mathrm{X}$ instrument dilution. Samples with coefficients of variation above $20 \%$ were also retested.

For all 55 control subjects, NFL concentrations were measured in serum collected at a single time point. For patients with COVID-19, NFL was measured in serum collected at a single time point for 42 individuals (29.6\% of patients) and in serum collected at multiple time points for the remaining patients. For patients who underwent longitudinal serum collection, the median number of NFL measurements was 4 (Range: 2 - 17).

\section{Statistical analysis}

Continuous variables were summarized with the sample median and range. Categorical variables were summarized with number and percentage of patients. Comparisons of NFL concentrations between controls and patients with COVID-19 were made using a Wilcoxon rank sum test in unadjusted analysis, and using a stratified van Elteren Wilcoxon rank sum test (39) in adjusted analysis, where the test was stratified by both age as a four-level categorical variable (based on sample quartiles) and sex. For comparisons of NFL 
between the control group and patients with COVID-19, single time point NFL concentrations of controls were compared to the following five NFL values in patients: 1: NFL in serum from the first blood draw, 2: NFL in serum from the last blood draw, 3: mean NFL concentration in all serum samples for a given patient, 4: minimum NFL concentration per patient, and 5: maximum NFL concentration per patient. In patients alone, we also assessed the strength of association between the length of time from admission to blood draw and NFL concentrations by estimating Spearman's correlation coefficient and by obtaining a p-value from a mixed effects linear regression model that included a random effect for patients. NFL was examined on the natural logarithm scale in this and all subsequently described analyses owing to its skewed distribution.

When assessing associations of NFL concentrations with outcomes (need for mechanical ventilation/intubation, ICU admission, LOS, mRS at discharge), we considered the five following patient-specific NFL variables: 1: mean NFL concentration per patient, 2: minimum NFL concentration per patient, 3: maximum NFL concentration per patient, 4: occurrence of an NFL concentration $>25^{\text {th }}$ percentile, and 5: occurrence of an NFL concentration $>75^{\text {th }}$ percentile. The $25^{\text {th }}$ and $75^{\text {th }}$ percentile cutoffs were calculated using all NFL concentrations in our cohort of patients with COVID-19.

Importantly, given that outcomes often occurred either prior to measurement of any NFL values (need for mechanical ventilation/intubation or ICU admission) or at a very similar time point as measurement of some NFL values (LOS and $\mathrm{mRS}$ at discharge), performing an analysis that examined the ability of NFL to predict these outcome measures was not possible given the data. Therefore, to assess whether NFL associates with poor outcomes in patients with COVID-19, we assessed associations between outcomes (intubation, ICU admission, length of hospital stay, and mRS at discharge) and each of the five aforementioned NFL variables using linear regression models (mean, minimum, and maximum NFL per patient) and logistic regression models (NFL $>25^{\text {th }}$ percentile and NFL $>75^{\text {th }}$ percentile), where the NFL variables were examined as the dependent variables in the regression models, and NFL values were included regardless of temporal relationship to time of start of mechanical ventilation (intubation) or time of ICU admission. Regression coefficients and 95\% confidence intervals (CIs) were estimated from linear regression models, whereas odds ratios (ORs) and $95 \%$ CIs were estimated from logistic regression models. Unadjusted models were first examined, and these were followed by multivariable models that were adjusted for age, sex, BMI, and CKD. The latter was included given that blood NFL concentrations are affected by renal function (40). Length of time from admission to blood draw was not initially taken into account in multivariable models as this variable can, to some extent, also be thought of as an outcome measure (as a longer time from admission to blood draw indicates a patient with a longer hospitalization and likely worse outcomes) and therefore may be on the causal pathway between NFL and outcomes (41). However, in a secondary analysis, we did examine the sensitivity of our results to additional multivariable adjustment for length of time from admission to final blood draw.

We examined whether specific COVID-19 treatments (monoclonal antibody, remdesivir, dexamethasone and convalescent plasma) associated with a lower or higher serum NFL as follows. First, to satisfy the statistical assumption of independent measurements, we performed two separate analyses using a single NFL value per patient (as many patients had multiple NFL values), with the first analysis utilizing the NFL concentration from the first blood draw for each patient, and the second analysis utilizing the NFL concentration in the final blood draw for each patient. For each of these two analyses, we compared serum NFL concentrations between patients who did and did not receive the given treatment (only NFL values that were measured after the given treatment were used for patients in a given "treatment" group) using linear regression models. Owing to the very strong confounding influence of time from admission to blood draw, we first adjusted models for this variable alone and then subsequently additionally adjusted for age, sex, and BMI. Regression coefficients and $95 \%$ CIs were estimated.

We utilized a Bonferroni correction for multiple testing separately for each family of similar statistical tests. After applying this correction, p-values $<0.0025$ were considered as statistically significant when evaluating associations of NFL with outcomes (4 different outcomes were examined for 5 NFL variables), and p-values $<0.0063$ were considered as statistically significant when assessing associations of NFL with COVID-19 treatment (4 different treatments were examined for 2 NFL variables). P-values $<0.05$ were considered as statistically significant in all other analyses. All statistical tests were two-sided and were performed using SAS (version 9.4; SAS Institute, Inc.).

\section{SUPPLEMENTARY MATERIALS}

stm.sciencemag.org/cgi/content/full/scitranslmed.abi7643/DC1 Tables S1 and S2

\section{REFERENCES AND NOTES}

1. https://coronavirus.jhu.edu/map.html.

2. H. A. Rothan, S. N. Byrareddy, The epidemiology and pathogenesis of coronavirus disease (COVID-19) outbreak. J. Autoimmun. 109, 102433 (2020). doi:10.1016/j.jaut.2020.102433 Medline

3. L. Mao, M. Wang, S. Chen, Q. He, J. Chang, C. Hong, Y. Zhou, D. Wang, Y. Li, H. Jin, B. Hu, Neurological Manifestations of Hospitalized Patients with COVID-19 in Wuhan, China: a retrospective case series study. medRxiv, 2020.2002.2022.20026500 (2020) 10.1101/2020.02.22.20026500).

4. A. Avula, K. Nalleballe, N. Narula, S. Sapozhnikov, V. Dandu, S. Toom, A. Glaser, D. Elsayegh, COVID-19 presenting as stroke. Brain Behav. Immun. 87, 115-119 (2020). doi:10.1016/j.bbi.2020.04.077 Medline

5. R. Beyrouti, M. E. Adams, L. Benjamin, H. Cohen, S. F. Farmer, Y. Y. Goh, F. 
Humphries, H. R. Jäger, N. A. Losseff, R. J. Perry, S. Shah, R. J. Simister, D. Turner, A. Chandratheva, D. J. Werring, Characteristics of ischaemic stroke associated with COVID-19. J. Neurol. Neurosurg. Psychiatry 91, 889-891 (2020). doi:10.1136/innn-2020-323586 Medline

6. T. González-Pinto, A. Luna-Rodríguez, A. Moreno-Estébanez, G. Agirre-Beitia, A. Rodríguez-Antigüedad, M. Ruiz-Lopez, Emergency room neurology in times of COVID-19: Malignant ischaemic stroke and SARS-CoV-2 infection. Eur. J. Neurol. 27, e35-e36 (2020). doi:10.1111/ene.14286 Medline

7. J. Helms, S. Kremer, H. Merdji, R. Clere-Jehl, M. Schenck, C. Kummerlen, 0. Collange, C. Boulay, S. Fafi-Kremer, M. Ohana, M. Anheim, F. Meziani, Neurologic Features in Severe SARS-CoV-2 Infection. N. Engl. J. Med. 382, 2268-2270 (2020). doi:10.1056/NEJMc2008597 Medline

8. J. Li, X. Long, Q. Zhang, X. Fang, F. Fang, X. Lv, D. Zhang, Y. Sun, N. Li, S. Hu, Z. Lin, $\mathrm{N}$. Xiong, Emerging evidence for neuropsycho-consequences of COVID-19. Curr. Neuropharmacol. 19, 92-96 (2021). doi:10.2174/1570159X18666200507085335 Medline

9. Y. Zhou, W. Li, D. Wang, L. Mao, H. Jin, Y. Li, C. Hong, S. Chen, J. Chang, Q. He, M. Wang, B. Hu, Clinical time course of COVID-19, its neurological manifestation and some thoughts on its management. Stroke Vasc. Neurol. 5, 177-179 (2020). doi:10.1136/svn-2020-000398 Medline

10. J. A. Frontera, D. Yang, A. Lewis, P. Patel, C. Medicherla, V. Arena, T. Fang, A. Andino, T. Snyder, M. Madhavan, D. Gratch, B. Fuchs, A. Dessy, M. Canizares, R. Jauregui, B. Thomas, K. Bauman, A. Olivera, D. Bhagat, M. Sonson, G. Park, R. Stainman, B. Sunwoo, D. Talmasov, M. Tamimi, Y. Zhu, J. Rosenthal, L. Dygert, M. Ristic, H. Ishii, E. Valdes, M. Omari, L. Gurin, J. Huang, B. M. Czeisler, D. E. Kahn, T. Zhou, J. Lin, A. S. Lord, K. Melmed, S. Meropol, A. B. Troxel, E. Petkova, T. Wisniewski, L. Balcer, C. Morrison, S. Yaghi, S. Galetta, A prospective study of long-term outcomes among hospitalized COVID-19 patients with and without neurological complications. J. Neurol. Sci. 426, 117486 (2021). doi:10.1016/i.jns.2021.117486 Medline

11. L. Mao, H. Jin, M. Wang, Y. Hu, S. Chen, Q. He, J. Chang, C. Hong, Y. Zhou, D. Wang, X. Miao, Y. Li, B. Hu, Neurologic Manifestations of Hospitalized Patients With Coronavirus Disease 2019 in Wuhan, China. JAMA Neurol. 77, 683-690 (2020). doi:10.1001/jamaneurol.2020.1127 Medline

12. M. Boldrini, P. D. Canoll, R. S. Klein, How COVID-19 Affects the Brain. JAMA Psychiatry 78, 682-683 (2021). doi:10.1001/jamapsychiatry.2021.0500 Medline

13. M. Greenway, Y. Erben, J. F. Huang, J. L. Siegel, C. J. Lamb, J. K. Badi, A. Sakusic, N. Gopal, J. F. Meschia, M. P. Lin, Yield of head imaging in ambulatory and hospitalized patients wtih SARS-Cov-2: A multi-center study of 8675 patients. Neurohospitalist (2020). 10.1177/1941874420980622

14. S. Katal, S. Balakrishnan, A. Gholamrezanezhad, Neuroimaging and neurologic findings in COVID-19 and other coronavirus infections: A systematic review in 116 patients. J. Neuroradiol. 48, 43-50 (2021). doi:10.1016/i.neurad.2020.06.007 Medline

15. S. Katal, A. Gholamrezanezhad, Neuroimaging findings in COVID-19: A narrative review. Neurosci. Lett. 742, 135529 (2021). doi:10.1016/i.neulet.2020.135529 Medline

16. R. R. Reichard, K. B. Kashani, N. A. Boire, E. Constantopoulos, Y. Guo, C. F. Lucchinetti, Neuropathology of COVID-19: A spectrum of vascular and acute disseminated encephalomyelitis (ADEM)-like pathology. Acta Neuropathol. 140, 1-6 (2020). doi:10.1007/s00401-020-02166-2 Medline

17. J. Matschke, M. Lütgehetmann, C. Hagel, J. P. Sperhake, A. S. Schröder, C. Edler, H. Mushumba, A. Fitzek, L. Allweiss, M. Dandri, M. Dottermusch, A. Heinemann, S. Pfefferle, M. Schwabenland, D. Sumner Magruder, S. Bonn, M. Prinz, C. Gerloff, K. Püschel, S. Krasemann, M. Aepfelbacher, M. Glatzel, Neuropathology of patients with COVID-19 in Germany: A post-mortem case series. Lancet Neurol. 19, 919929 (2020). doi:10.1016/S1474-4422(20)30308-2 Medline

18. G. E. Serrano, J. E. Walker, R. Arce, M. J. Glass, D. Vargas, L. I. Sue, A. J. Intorcia, C. M. Nelson, J. Oliver, J. Papa, A. Russell, K. E. Suszczewicz, C. I. Borja, C. Belden, D. Goldfarb, D. Shprecher, A. Atri, C. H. Adler, H. A. Shill, E. Driver-Dunckley, S. H. Mehta, B. Readhead, M. J. Huentelman, J. L. Peters, E. Alevritis, C. Bimi, J. P. Mizgerd, E. M. Reiman, T. J. Montine, M. Desforges, J. L. Zehnder, M. K. Sahoo, H. Zhang, D. Solis, B. A. Pinsky, M. Deture, D. W. Dickson, T. G. Beach, Mapping of SARS-CoV-2 Brain Invasion and Histopathology in COVID-19 Disease. medRxiv 2021.2002.2015.21251511 (2021). 10.1101/2021.02.15.21251511 Medline
19. T. F. Gendron, M. K. Badi, M. G. Heckman, K. R. Jansen-West, G. K. Vilanilam, P. W. Johnson, A. R. Burch, R. L. Walton, O. A. Ross, T. G. Brott, T. M. Miller, J. D. Berry, K. A. Nicholson, Z. K. Wszolek, B. E. Oskarsson, K. N. Sheth, L. H. Sansing, G. J. Falcone, B. L. Cucchiara, J. F. Meschia, L. Petrucelli, Plasma neurofilament light predicts mortality in patients with stroke. Sci. Transl. Med. 12, eaay1913 (2020). doi:10.1126/scitranslmed.aay 1913 Medline

20. C. Barro, H. Zetterberg, Neurological symptoms and blood neurofilament light levels. Acta Neurol. Scand. 144, 13-20 (2021). doi:10.1111/ane.13415 Medline

21. M. Al Hussona, M. Maher, D. Chan, J. A. Micieli, J. D. Jain, H. Khosravani, A. Izenberg, C. D. Kassardjian, S. B. Mitchell, The Virtual Neurologic Exam: Instructional Videos and Guidance for the COVID-19 Era. Can. J. Neurol. Sci. 47, 598-603 (2020). doi:10.1017/cin.2020.96 Medline

22. K. Ganapathy, Telemedicine and Neurological Practice in the COVID-19 Era. Neurol. India 68, 555-559 (2020). doi:10.4103/0028-3886.288994 Medline

23. M. Ameres, S. Brandstetter, A. A. Toncheva, M. Kabesch, D. Leppert, J. Kuhle, S. Wellmann, Association of neuronal injury blood marker neurofilament light chain with mild-to-moderate COVID-19. J. Neurol. 267, 3476-3478 (2020). do::10.1007/s00415-020-10050-y Medline

24. N. Kanberg, N. J. Ashton, L.-M. Andersson, A. Yilmaz, M. Lindh, S. Nilsson, R. W. Price, K. Blennow, H. Zetterberg, M. Gisslén, Neurochemical evidence of astrocytic and neuronal injury commonly found in COVID-19. Neurology 95, e1754-e1759 (2020). doi:10.1212/WNL.0000000000010111 Medline

25. R. Sutter, L. Hert, G. M. De Marchis, R. Twerenbold, L. Kappos, Y. Naegelin, G. M. Kuster, P. Benkert, J. Jost, A. M. Maceski, S. Rüegg, M. Siegemund, D. Leppert, S. Tschudin-Sutter, J. Kuhle, Serum Neurofilament Light Chain Levels in the Intensive Care Unit: Comparison between Severely III Patients with and without Coronavirus Disease 2019. Ann. Neurol. 89, 610-616 (2021). doi:10.1002/ana.26004 Medline

26. A. Edén, N. Kanberg, J. Gostner, D. Fuchs, L. Hagberg, L.-M. Andersson, M. Lindh, R. W. Price, H. Zetterberg, M. Gisslén, CSF Biomarkers in Patients With COVID-19 and Neurologic Symptoms: A Case Series. A Case Series 96, e294-e300 (2021). Medline

27. M. Desforges, A. Le Coupanec, P. Dubeau, A. Bourgouin, L. Lajoie, M. Dubé, P. J. Talbot, Human Coronaviruses and Other Respiratory Viruses: Underestimated Opportunistic Pathogens of the Central Nervous System? Viruses 12, 14 (2019). doi:10.3390/v12010014 Medline

28. K. Bohmwald, N. M. S. Gálvez, M. Ríos, A. M. Kalergis, Neurologic Alterations Due to Respiratory Virus Infections. Front. Cell. Neurosci. 12, 386 (2018). doi:10.3389/fncel.2018.00386 Medline

29. A. Achar, C. Ghosh, COVID-19-Associated Neurological Disorders: The Potential Route of CNS Invasion and Blood-Brain Relevance. Cells 9, 2360 (2020). doi:10.3390/cells 9112360 Medline

30. N. Deigendesch, L. Sironi, M. Kutza, S. Wischnewski, V. Fuchs, J. Hench, A. Frank, R. Nienhold, K. D. Mertz, G. Cathomas, M. S. Matter, M. Siegemund, M. Tolnay, L. Schirmer, A. K. Pröbstel, A. Tzankov, S. Frank, Correlates of critical illness-related encephalopathy predominate postmortem COVID-19 neuropathology. Acta Neuropathol. 140, 583-586 (2020). doi:10.1007/s00401-020-02213-y Medline

31. https://www.idsociety.org/covid-19-real-time-learning-network/therapeuticsand-interventions/corticosteroids/.

32. https://www.fda.gov/news-events/press-announcements/coronavirus-covid19-update-fda-authorizes-monoclonal-antibodies-treatment-covid-19-0.

33. https://www.idsociety.org/covid-19-real-time-learning-network/therapeuticsand-interventions/remdesivir/.

34. J. J. Malin, I. Suárez, V. Priesner, G. Fätkenheuer, J. Rybniker, Remdesivir against COVID-19 and Other Viral Diseases. Clin. Microbiol. Rev. 34, ... (2020). doi:10.1128/CMR.00162-20 Medline

35. https://www.covid19treatmentguidelines,nih.gov/whats-new/

36. A. R.-M. C Avendaño-Solà, E Muñez-Rubio, B Ruiz-Antorán, R Malo de Molina, F Torres, A Fernández-Cruz, A Callejas-Díaz, J Calderón, C Payares-Herrera, I Salcedo, I Romera, J Lora-Tamayo, M Mancheño-Losa, ML Paciello, C Villegas, V Estrada, I Saez-Serrano, ML Porras-Leal, MC Jarilla-Fernández, JR Paño-Pardo, JA Moreno-Chulilla, I Arrieta-Aldea, A Bosch, M Belhassen-Garcia, O López-Villar, A Ramos-Garrido, L Blanco, ME Madrigal-Sánchez, E Contreras, E Muñiz-Díaz, JM Domingo-Morera, I Casas-Flecha, M Pérez-Olmeda, Javier Garcia-Pérez, J Alcamí, JL Bueno, RF Duarte, for the ConPlas-19 Study Group, 
(https://doi.org/10.1101/2020.08.26.20182444).

37. A. Pilotto, V. Cristillo, S. C. Piccinelli, N. Zoppi, G. Bonzi, D. Sattin, S. Schiavolin, A. Raggi, A. Canale, S. Gipponi, I. Libri, M. Frigerio, M. Bezzi, M. Leonardi, A. Padovani, COVID-19 severity impacts on long-term neurological manifestation after hospitalisation. medRxiv, 2020.2012.2027.20248903 (2021)10.1101/2020.12.27.20248903)

38. A. Nunn, P. M. Bath, L. J. Gray, Analysis of the Modified Rankin Scale in Randomised Controlled Trials of Acute Ischaemic Stroke: A Systematic Review. Stroke Res. Treat. 2016, 9482876 (2016). doi:10.1155/2016/9482876 Medline

39. P. H. van Elteren, On the combination of independent two-sample tests of Wilcoxon. Bulletin of the International Statistical Institute, 351-361 (1960).

40. S. Akamine, N. Marutani, D. Kanayama, S. Gotoh, R. Maruyama, K. Yanagida, Y. Sakagami, K. Mori, H. Adachi, J. Kozawa, N. Maeda, M. Otsuki, T. Matsuoka, H. Iwahashi, I. Shimomura, M. Ikeda, T. Kudo, Renal function is associated with blood neurofilament light chain level in older adults. Sci. Rep. 10, 20350 (2020). doi:10.1038/s41598-020-76990-7 Medline

41. E. F. Schisterman, S. R. Cole, R. W. Platt, Overadjustment bias and unnecessary adjustment in epidemiologic studies. Epidemiology 20, 488-495 (2009). doi:10.1097/EDE.0b013e3181a819a1 Medline

Acknowledgments: We thank the COVID-19 Task Force for their support in conducting this research study. We are grateful to all individuals who donated samples. We also thank Rana Shukri Hanna AI Shaikh for verifying healthy control demographic information. Funding: This work was supported by National Institutes of Health grant RF1 NS120992 (to MP), National Institutes of Health grant R35 NS097273 (to LP), National Institutes of Health grant P01 NS084974 (to LP), National Institutes of Health grant P01 NS099114 (to TFG and LP), National Institutes of Health grant U01 NS080168 (to JFM), National Institutes of Health grant U19 NS115388 (to JFM), The Earl \& Nyda Swanson Neurosciences Research Fund (to JFM), The Harley N and Rebecca N Hotchkiss Endowed Fund in Neuroscience Research, Honoring Ken and Marietta (to JFM), The Donald G and Jodi P Heeringa Family (to ZKW and LP), Mayo Clinic Center for

Regenerative Medicine (to ZKW), Mayo Clinic in Florida Focused Research Team Program (to ZKW), Gifts from The Sol Goldman Charitable Trust, the Haworth
Family Professorship in Neurodegenerative Diseases fund, and The Albertson Parkinson's Research Foundation (to ZKW). Author contributions: Conceptualization and/or study design: M.P., Y.M.E., J.F.M., L.P.; Collection of patient samples and/or clinical data: M.P., Y.M.E., C.P.M., K.R.J.-W., C.F.-M., C.N.C., M.T.L., Y.S., J.A.D., C.F.H., B.E.O., Z.K.W., L.J.H., J.C.O., J.B.H.; Perform NFL measurements and/or analyses of NFL concentrations: M.P., K.R.J.-W., T.F.G.; Statistical analyses: M.G.H., L.J.W. Writing: M.P., Y.M.E., M.G.H., T.F.G., J.F.M., L.P.; all authors read the paper and provided comments and revisions. Competing interests: B.O. has consulted for Biogen, MediciNova, Mitsubishi, Amylyx, and Tsumura. K.A.N. has performed consulting for Alector, Al Therapeutics, Biogen, MT Pharma, Avanir Pharmaceuticals, and Biohaven. JBH is the CLIA director for the Lung Bioengineering facility at Mayo Clinic Florida campus, a non-Mayo corporation. Z.K.W also serves as PI or Co-PI on Biogen, Inc. (228PD201), Biohaven Pharmaceuticals, Inc. (BHV4157-206 and BHV3241301), and Neuraly, Inc. (NLY01-PD-1) grants; as well as a Co-PI of the Mayo Clinic APDA Center for Advanced Research. L.P. is a consultant for Expansion

Therapeutics. The other authors declare that they have no competing interests. Data and materials availability: All data associated with this study are present in the paper or the Supplementary Materials. Requests for clinical data should be addressed to L.P. and J.F.M. and will be made available through a data transfer agreement. This work is licensed under a Creative Commons Attribution 4.0 International (CC BY 4.0) license, which permits unrestricted use, distribution, and reproduction in any medium, provided the original work is properly cited. To view a copy of this license, visit https://creativecommons.org/licenses/by/4.0/. This license does not apply to figures/photos/artwork or other content included in the article that is credited to a third party; obtain authorization from the rights holder before using this material.

Submitted 2 April 2021

Accepted 9 June 2021

Published First Release 15 June 2021

10.1126/scitransImed.abi7643 
A

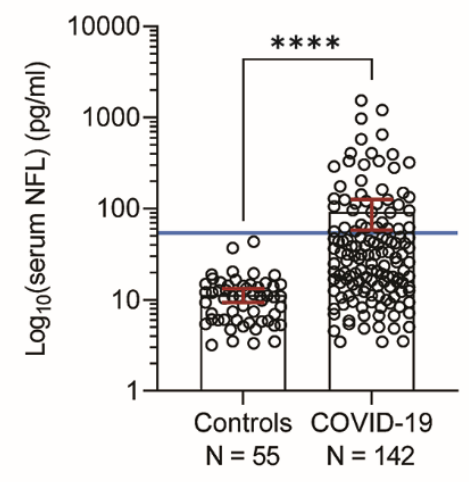

B

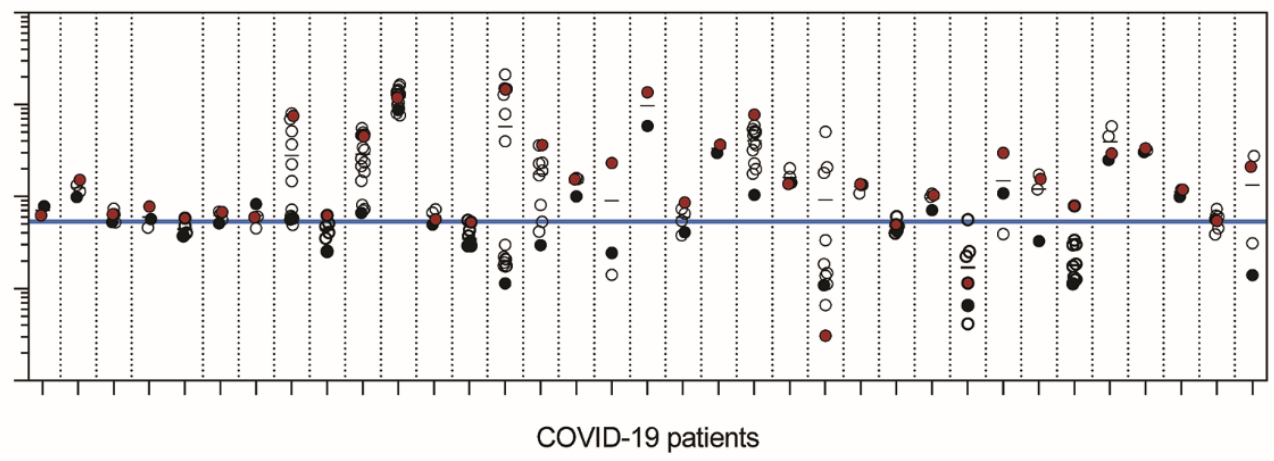

C

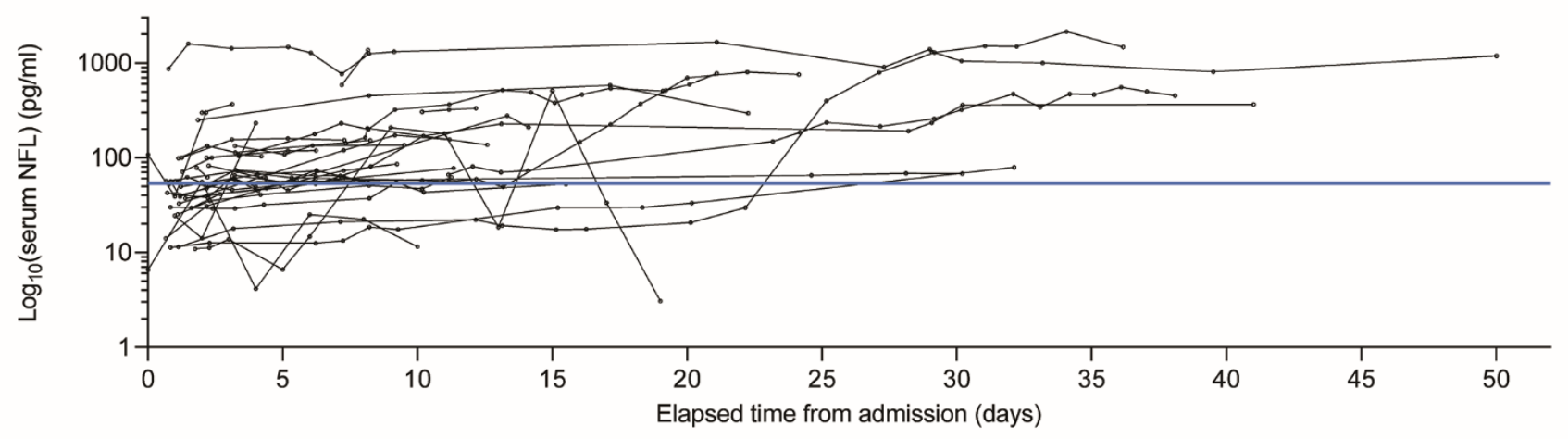

Fig. 1. Serum NFL is elevated in hospitalized patients with COVID-19. (A) Comparison of serum NFL between healthy controls (Controls, N=55) and hospitalized patients with COVID-19 (mean NFL per patient, $\mathrm{N}=142$ ). Bars represent mean NFL concentrations with $95 \%$ Cls. Statistical differences were assessed using a stratified van Elteren Wilcoxon rank sum test, where the test was stratified by both age as a four-level categorical variable (based on sample quartiles) and sex. ${ }^{* * *} \mathrm{P}<0.001$. (B) Serum NFL in 35 patients to highlight the range of NFL concentrations in longitudinally collected samples. The first and last NFL concentrations are indicated by a black and red dot, respectively, and mean concentrations for each patient are presented by the small black solid horizontal lines. (C) Serum NFL trends over time in the 35 patients with COVID-19 with longitudinal blood draws and for whom at least one NFL measurement is at least 3 standard deviations above the group mean of NFL in control individuals. NFL concentrations are shown on the base 10 logarithm scale. The NFL concentration representing the mean control NFL + 3 standard deviations is indicated by a solid blue horizontal line. 
Table 1. Characteristics, treatment, and outcomes for patients with COVID-19.

\begin{tabular}{|c|c|c|}
\hline Variable & $\mathrm{N}$ & Median (minimum, maximum) or No. (\%) \\
\hline \multicolumn{3}{|l|}{ Patient characteristics } \\
\hline Age at admission (years) & 142 & $62(22,99)$ \\
\hline Sex (Male) & 142 & $82(57.7 \%)$ \\
\hline Race & 142 & \\
\hline White & & $96(67.6 \%)$ \\
\hline Black & & $32(22.5 \%)$ \\
\hline Asian & & $12(8.5 \%)$ \\
\hline Other or not disclosed & & $2(1.4 \%)$ \\
\hline BMI & 142 & $30.0(15.3,80.1)$ \\
\hline Obesity & 142 & $71(50.0 \%)$ \\
\hline Chronic kidney disease (CKD) & 142 & $17(12.0 \%)$ \\
\hline Length of time from admission to first NFL (days) & 142 & $1(0,32)$ \\
\hline Number of NFL measurements & 142 & \\
\hline 1 & & $42(29.6 \%)$ \\
\hline 2 & & $20(14.1 \%)$ \\
\hline 3 & & $29(20.4 \%)$ \\
\hline 4 & & $24(16.9 \%)$ \\
\hline 5 & & $8(5.6 \%)$ \\
\hline$>5$ & & $19(13.4 \%)$ \\
\hline \multicolumn{3}{|l|}{ Treatments } \\
\hline Monoclonal antibody & 142 & $37(26.1 \%)$ \\
\hline Remdesivir & 142 & $106(74.6 \%)$ \\
\hline Dexamethasone therapy & 142 & $116(81.7 \%)$ \\
\hline Convalescent plasma & 142 & $44(31.0 \%)$ \\
\hline \multicolumn{3}{|l|}{ Outcomes } \\
\hline Mechanical ventilation (intubation) & 142 & $30(21.1 \%)$ \\
\hline ICU admission & 142 & $54(38.0 \%)$ \\
\hline Length of hospital stay (days) & 142 & $9(2,119)$ \\
\hline Death & 142 & $13(9.2 \%)$ \\
\hline $\mathrm{mRS}$ at discharge & 142 & \\
\hline 0 & & $1(0.7 \%)$ \\
\hline 1 & & $40(28.2 \%)$ \\
\hline 2 & & $35(24.6 \%)$ \\
\hline 3 & & $33(23.2 \%)$ \\
\hline 4 & & $15(10.6 \%)$ \\
\hline 5 & & $7(4.9 \%)$ \\
\hline 6 & & $11(7.7 \%)$ \\
\hline
\end{tabular}

ICU=Intensive Care Unit; BMI=Body mass index; $\mathrm{CKD}=$ Chronic Kidney Disease; mRS=modified Rankin Scale. 
Table 2. Comparison of serum NFL between healthy controls and patients with COVID-19.

\begin{tabular}{|c|c|c|c|c|}
\hline & \multirow[b]{2}{*}{$\mathrm{N}$} & \multirow[b]{2}{*}{$\begin{array}{l}\text { Median (minimum, } \\
\text { maximum) NFL } \\
\text { concentration }\end{array}$} & \multicolumn{2}{|c|}{ P-value vs. controls } \\
\hline & & & Unadjusted & $\begin{array}{l}\text { Adjusting for age } \\
\text { and sex }\end{array}$ \\
\hline Healthy controls & 55 & $10.9(3.2,43.2)$ & N/A & N/A \\
\hline Patients with COVID-19 & & & & \\
\hline First NFL measurement & 142 & $21.8(2.9,1538.4)$ & $<0.001$ & $<0.001$ \\
\hline Final NFL measurement & 142 & $32.3(2.2,1538.4)$ & $<0.001$ & $<0.001$ \\
\hline Mean NFL per patient & 142 & $29.4(3.4,1538.4)$ & $<0.001$ & $<0.001$ \\
\hline Minimum NFL per patient & 142 & $20.3(2.2,1538.4)$ & $<0.001$ & $<0.001$ \\
\hline Maximum NFL per patient & 142 & $37.9(3.4,2131.0)$ & $<0.001$ & $<0.001$ \\
\hline
\end{tabular}

In unadjusted analyses, $p$-values result from a Wilcoxon rank sum test. In adjusted analyses, $p$-values result from a stratified van Elteren Wilcoxon rank sum test, where the test was stratified by both age as a four-level categorical variable (based on sample quartiles) and sex 
Table 3. Associations between serum NFL and outcomes in patients with COVID-19.

\begin{tabular}{|c|c|c|c|c|c|c|c|}
\hline \multirow{3}{*}{$\begin{array}{l}\text { Association examined } \\
\text { Association between } \\
\text { intubation and: }\end{array}$} & & & \multirow{3}{*}{$\begin{array}{l}\text { Association } \\
\text { measure }\end{array}$} & \multicolumn{2}{|c|}{ Unadjusted analysis } & \multicolumn{2}{|c|}{$\begin{array}{l}\text { Adjusting for age, sex, } \\
\text { BMI, and CKD }\end{array}$} \\
\hline & \multicolumn{2}{|c|}{$\begin{array}{l}\text { Median (minimum, maximum) } \\
\text { NFL or No. (\%) for the given } \\
\text { group }\end{array}$} & & $\begin{array}{l}\text { Estimate } \\
(95 \% \mathrm{CI})\end{array}$ & $\begin{array}{c}\mathrm{P}- \\
\text { value }\end{array}$ & $\begin{array}{l}\text { Estimate } \\
(95 \% \mathrm{CI})\end{array}$ & P-value \\
\hline & $\begin{array}{c}\text { No intubation } \\
(\mathrm{N}=112)\end{array}$ & $\begin{array}{l}\text { Intubation } \\
(\mathrm{N}=30)\end{array}$ & & & & & \\
\hline Mean NFL per patient & $19.7(3.4,972.7)$ & $\begin{array}{l}107.4(15.9, \\
1538.4)\end{array}$ & $\begin{array}{l}\text { Regression } \\
\text { coefficient }\end{array}$ & $\begin{array}{l}1.61(1.16, \\
2.06)\end{array}$ & $<0.001$ & $\begin{array}{l}1.66(1.24, \\
2.07)\end{array}$ & $<0.001$ \\
\hline $\begin{array}{l}\text { Minimum NFL per } \\
\text { patient }\end{array}$ & $16.6(2.2,585.6)$ & $\begin{array}{c}50.3(3.1 \\
1538.4)\end{array}$ & $\begin{array}{l}\text { Regression } \\
\text { coefficient }\end{array}$ & $\begin{array}{l}1.25(0.78 \\
1.72)\end{array}$ & $<0.001$ & $\begin{array}{l}1.31(0.87 \\
1.75)\end{array}$ & $<0.001$ \\
\hline $\begin{array}{l}\text { Maximum NFL per } \\
\text { patient }\end{array}$ & $\begin{array}{l}22.2(3.4, \\
1359.7)\end{array}$ & $\begin{array}{l}111.5(15.9 \\
2131.0)\end{array}$ & $\begin{array}{l}\text { Regression } \\
\text { coefficient }\end{array}$ & $\begin{array}{l}1.75(1.27 \\
2.24)\end{array}$ & $<0.001$ & $\begin{array}{l}1.79(1.35 \\
2.24)\end{array}$ & $<0.001$ \\
\hline $\begin{array}{l}\text { NFL value }>25^{\text {th }} \\
\text { percentile }\end{array}$ & $74(66.1 \%)$ & $30(100.0 \%)$ & Odds ratio & $\mathrm{N} / \mathrm{A}^{1}$ & $<0.001$ & $\mathrm{~N} / \mathrm{A}^{1}$ & $\mathrm{~N} / \mathrm{A}^{1}$ \\
\hline $\begin{array}{l}\text { NFL value }>75^{\text {th }} \\
\text { percentile }\end{array}$ & $15(13.4 \%)$ & $19(63.3 \%)$ & Odds ratio & $\begin{array}{l}11.17(4.45 \\
28.03)\end{array}$ & $<0.001$ & $\begin{array}{l}10.64(3.80 \\
29.80)\end{array}$ & $<0.001$ \\
\hline $\begin{array}{l}\text { Association between ICU } \\
\text { admission and: }\end{array}$ & $\begin{array}{l}\text { No ICU } \\
\text { admission } \\
(\mathrm{N}=88)\end{array}$ & $\begin{array}{c}\text { ICU } \\
\text { admission } \\
(\mathrm{N}=54)\end{array}$ & & & & & \\
\hline Mean NFL per patient & $18.7(3.4,972.7)$ & $\begin{array}{l}52.2(4.8 \\
1538.4)\end{array}$ & $\begin{array}{l}\text { Regression } \\
\text { coefficient }\end{array}$ & $\begin{array}{l}1.10(0.69 \\
1.50)\end{array}$ & $<0.001$ & $\begin{array}{l}1.13(0.76 \\
1.49)\end{array}$ & $<0.001$ \\
\hline $\begin{array}{l}\text { Minimum NFL per } \\
\text { patient }\end{array}$ & $15.8(2.2,585.6)$ & $\begin{array}{l}33.2(3.1 \\
1538.4)\end{array}$ & $\begin{array}{l}\text { Regression } \\
\text { coefficient }\end{array}$ & $\begin{array}{l}0.82(0.411 \\
1.23)\end{array}$ & $<0.001$ & $\begin{array}{l}0.86(0.48 \\
1.24)\end{array}$ & $<0.001$ \\
\hline $\begin{array}{l}\text { Maximum NFL per } \\
\text { patient }\end{array}$ & $\begin{array}{c}20.4(3.4 \\
1359.7)\end{array}$ & $\begin{array}{l}64.5(7.9 \\
2131.0)\end{array}$ & $\begin{array}{l}\text { Regression } \\
\text { coefficient }\end{array}$ & $\begin{array}{l}1.23(0.80 \\
1.66)\end{array}$ & $<0.001$ & $\begin{array}{c}1.26(0.87 \\
1.65)\end{array}$ & $<0.001$ \\
\hline $\begin{array}{l}\text { NFL value }>25^{\text {th }} \\
\text { percentile }^{1}\end{array}$ & $55(62.5 \%)$ & $49(90.7 \%)$ & Odds ratio & $\begin{array}{l}5.88(2.13 \\
16.25)\end{array}$ & $<0.001$ & $\begin{array}{l}9.84(3.00, \\
32.29)\end{array}$ & $<0.001$ \\
\hline $\begin{array}{l}\text { NFL value }>75^{\text {th }} \\
\text { percentile }\end{array}$ & $10(11.4 \%)$ & $24(44.4 \%)$ & Odds ratio & $\begin{array}{l}6.24(2.67 \\
14.59)\end{array}$ & $<0.001$ & $\begin{array}{l}8.00(3.08 \\
20.75)\end{array}$ & $<0.001$ \\
\hline $\begin{array}{l}\text { Association between } \\
\text { length of hospital stay } \\
\text { and: }\end{array}$ & $\begin{array}{c}\mathrm{LOS} \leq 9 \text { days } \\
\quad(\mathrm{N}=79)\end{array}$ & $\begin{array}{l}\text { LOS }>9 \text { days } \\
\quad(\mathrm{N}=63)\end{array}$ & & & & & \\
\hline Mean NFL per patient & $15.9(3.4,972.7)$ & $\begin{array}{l}47.8(4.8 \\
1538.4)\end{array}$ & $\begin{array}{l}\text { Regression } \\
\text { coefficient }\end{array}$ & $\begin{array}{l}0.81(0.60 \\
1.01)\end{array}$ & $<0.001$ & $\begin{array}{l}0.74(0.55 \\
0.93)\end{array}$ & $<0.001$ \\
\hline $\begin{array}{l}\text { Minimum NFL per } \\
\text { patient }\end{array}$ & $13.9(2.2,585.6)$ & $\begin{array}{c}33.4(3.1 \\
1538.4)\end{array}$ & $\begin{array}{l}\text { Regression } \\
\text { coefficient }\end{array}$ & $\begin{array}{l}0.66(0.44 \\
0.87)\end{array}$ & $<0.001$ & $\begin{array}{l}0.60(0.40 \\
0.80)\end{array}$ & $<0.001$ \\
\hline $\begin{array}{l}\text { Maximum NFL per } \\
\text { patient }\end{array}$ & $\begin{array}{c}18.6(3.4 \\
1359.7)\end{array}$ & $\begin{array}{l}66.4(7.9 \\
2131.0)\end{array}$ & $\begin{array}{l}\text { Regression } \\
\text { coefficient }\end{array}$ & $\begin{array}{l}0.89(0.67 \\
1.10)\end{array}$ & $<0.001$ & $\begin{array}{l}0.82(0.62 \\
1.02)\end{array}$ & $<0.001$ \\
\hline $\begin{array}{l}\text { NFL value }>25^{\text {th }} \\
\text { percentile }^{1}\end{array}$ & $45(57.0 \%)$ & $59(93.7 \%)$ & Odds ratio & $\begin{array}{l}5.34(2.53 \\
11.24)\end{array}$ & $<0.001$ & $\begin{array}{l}4.90(2.27 \\
10.62)\end{array}$ & $<0.001$ \\
\hline $\begin{array}{l}\text { NFL value }>75^{\text {th }} \\
\text { percentile }\end{array}$ & $8(10.1 \%)$ & $26(41.3 \%)$ & Odds ratio & $\begin{array}{l}3.17(1.91 \\
5.24)\end{array}$ & $<0.001$ & $\begin{array}{l}3.24(1.92, \\
5.47)\end{array}$ & $<0.001$ \\
\hline $\begin{array}{l}\text { Association between } \\
\text { mRS at discharge and: }\end{array}$ & $\begin{array}{c}\mathrm{mRS} \text { at } \\
\text { discharge } \leq 3 \\
(\mathrm{~N}=109)\end{array}$ & $\begin{array}{c}\mathrm{mRS} \text { at } \\
\text { discharge }>3 \\
(\mathrm{~N}=33)\end{array}$ & & & & & \\
\hline Mean NFL per patient & $19.5(3.4,405.3)$ & $\begin{array}{l}91.9(17.9 \\
1538.4)\end{array}$ & $\begin{array}{l}\text { Regression } \\
\text { coefficient }\end{array}$ & $\begin{array}{l}0.56(0.46 \\
\quad 0.67)\end{array}$ & $<0.001$ & $\begin{array}{l}0.54(0.42 \\
\quad 0.66)\end{array}$ & $<0.001$ \\
\hline $\begin{array}{l}\text { Minimum NFL per } \\
\text { patient }\end{array}$ & $14.7(2.2,304.9)$ & $\begin{array}{l}47.8(3.1 \\
1538.4)\end{array}$ & $\begin{array}{l}\text { Regression } \\
\text { coefficient }\end{array}$ & $\begin{array}{l}0.49(0.38 \\
\quad 0.61)\end{array}$ & $<0.001$ & $\begin{array}{l}0.45(0.33 \\
0.58)\end{array}$ & $<0.001$ \\
\hline
\end{tabular}




\begin{tabular}{|c|c|c|c|c|c|c|c|}
\hline $\begin{array}{l}\text { Maximum NFL per } \\
\text { patient }\end{array}$ & $21.4(3.4,779.0)$ & $\begin{array}{l}105.0(18.1 \\
2131.0)\end{array}$ & $\begin{array}{l}\text { Regression } \\
\text { coefficient }\end{array}$ & $\begin{array}{c}0.60(0.48, \\
0.71)\end{array}$ & $<0.001$ & $\begin{array}{c}0.58(0.46 \\
0.71)\end{array}$ & $<0.001$ \\
\hline $\begin{array}{l}\text { NFL value }>25^{\text {th }} \\
\text { percentile }^{1}\end{array}$ & $71(65.1 \%)$ & 33 (100.0\%) & Odds ratio & $\begin{array}{c}3.67(2.17 \\
6.22)\end{array}$ & $<0.001$ & $\begin{array}{c}3.00(1.71 \\
5.29)\end{array}$ & $<0.001$ \\
\hline $\begin{array}{l}\text { NFL value }>75^{\text {th }} \\
\text { percentile }\end{array}$ & $16(14.7 \%)$ & $18(54.5 \%)$ & Odds ratio & $\begin{array}{l}2.27(1.66 \\
3.11)\end{array}$ & $<0.001$ & $\begin{array}{c}3.04(2.02, \\
4.58)\end{array}$ & $<0.001$ \\
\hline
\end{tabular}

$\mathrm{CI}=$ confidence interval; LOS=length of hospital stay; BMI=Body mass index; CKD=Chronic Kidney Disease; mRS= modified Rankin Scale. For descriptive summaries of NFL concentration, for ease of presentation LOS was categorized using the sample median, whereas $\mathrm{mRS}$ at discharge was categorized using a pre-defined cutoff of interest. Associations of intubation, ICU admission, length of hospital stay, and mRS at discharge (all as independent variables) with NFL concentration (as the dependent variable) were evaluated using linear regression models (for the continuous mean NFL per patient, minimum NFL per patient, and maximum NFL per patient variables) and logistic regression models (for the binary occurrence of an NFL value $>25^{\text {th }}$ percentile and occurrence of an NFL value $>75^{\text {th }}$ percentile variables). Regression coefficients are interpreted as the change in the mean NFL outcome measure (on the natural logarithm scale) corresponding to presence of the given characteristic (intubation and ICU admission), to each doubling of length of hospital stay, and to each 1-unit increase in mRS at discharge. ${ }^{1}$ When evaluating the association between intubation and NFL value $>25^{\text {th }}$ percentile, logistic regression was not possible owing to the occurrence of a zero cell count. Therefore, the p-value in unadjusted analysis results from Fisher's exact test, and multivariable analysis was not performed. P-values $<0.0025$ were considered as statistically significant after applying a Bonferroni correction for multiple testing. 
Table 4. Comparison of serum NFL concentrations according to COVID-19 treatment.

\begin{tabular}{|c|c|c|c|c|c|c|}
\hline \multirow[b]{2}{*}{ COVID-19 treatment } & \multirow[b]{2}{*}{$\mathrm{N}$} & \multirow[b]{2}{*}{$\begin{array}{l}\text { Median (minimum, } \\
\text { maximum) NFL } \\
\text { concentration }\end{array}$} & \multicolumn{2}{|c|}{$\begin{array}{l}\text { Adjusting for time from } \\
\text { admission to blood draw }\end{array}$} & \multicolumn{2}{|c|}{$\begin{array}{l}\text { Adjusting for age, sex, BMI, } \\
\text { and time from admission to } \\
\text { blood draw }\end{array}$} \\
\hline & & & $\begin{array}{l}\text { Regression } \\
\text { coefficient }(95 \% \\
\text { CI) }\end{array}$ & $\begin{array}{l}\mathrm{P}- \\
\text { value }\end{array}$ & $\begin{array}{l}\text { Regression } \\
\text { coefficient }(95 \% \\
\text { CI) }\end{array}$ & P-value \\
\hline \multicolumn{7}{|l|}{$\begin{array}{l}\text { Monoclonal antibody } \\
\text { treatment }\end{array}$} \\
\hline \multicolumn{7}{|c|}{ First NFL value per patient } \\
\hline No treatment & 125 & $22.5(2.9,1538.4)$ & 1.00 (reference) & N/A & 1.00 (reference) & $\mathrm{N} / \mathrm{A}$ \\
\hline Treatment & 17 & $20.0(3.5,647.3)$ & $-0.34(-0.91,0.23)$ & 0.29 & $-0.47(-1.00,0.05)$ & 0.074 \\
\hline \multicolumn{7}{|c|}{ Final NFL value per patient } \\
\hline No treatment & 107 & $31.1(2.2,1538.4)$ & 1.00 (reference) & $\mathrm{N} / \mathrm{A}$ & 1.00 (reference) & $\mathrm{N} / \mathrm{A}$ \\
\hline Treatment & 35 & $33.4(3.1,1465.8)$ & $-0.38(-0.85,0.09)$ & 0.12 & $-0.39(-0.84,0.07)$ & 0.094 \\
\hline \multicolumn{7}{|l|}{ Remdesevir treatment } \\
\hline \multicolumn{7}{|c|}{ First NFL value per patient } \\
\hline No treatment & 92 & $21.2(2.9,872.3)$ & 1.00 (reference) & $\mathrm{N} / \mathrm{A}$ & 1.00 (reference) & $\mathrm{N} / \mathrm{A}$ \\
\hline Treatment & 50 & $23.7(3.4,1538.4)$ & $-0.25(-0.68,0.18)$ & 0.25 & $-0.24(-0.64,0.15)$ & 0.23 \\
\hline \multicolumn{7}{|c|}{ Final NFL value per patient } \\
\hline No treatment & 42 & $32.3(3.4,1359.7)$ & 1.00 (reference) & $\mathrm{N} / \mathrm{A}$ & 1.00 (reference) & $\mathrm{N} / \mathrm{A}$ \\
\hline Treatment & $\begin{array}{l}10 \\
0\end{array}$ & $32.1(2.2,1538.4)$ & $\begin{array}{l}-0.47(-0.89,- \\
0.05)\end{array}$ & 0.029 & $-0.56(-0.97,-0.15)$ & 0.008 \\
\hline \multicolumn{7}{|c|}{ Dexamethasone treatment } \\
\hline \multicolumn{7}{|c|}{ First NFL value per patient } \\
\hline No treatment & 103 & $21.4(2.9,1538.4)$ & 1.00 (reference) & $\mathrm{N} / \mathrm{A}$ & 1.00 (reference) & $\mathrm{N} / \mathrm{A}$ \\
\hline Treatment & 39 & $22.5(3.4,872.3)$ & $0.27(-0.16,0.69)$ & 0.22 & $0.26(-0.13,0.64)$ & 0.19 \\
\hline \multicolumn{7}{|c|}{ Final NFL value per patient } \\
\hline No treatment & 66 & $29.3(2.2,1538.4)$ & 1.00 (reference) & $\mathrm{N} / \mathrm{A}$ & 1.00 (reference) & $\mathrm{N} / \mathrm{A}$ \\
\hline Treatment & 76 & $37.8(3.1,1465.8)$ & $-0.11(-0.51,0.29)$ & 0.59 & $-0.08(-0.46,0.31)$ & 0.69 \\
\hline \multicolumn{7}{|l|}{$\begin{array}{l}\text { Convalescent plasma } \\
\text { treatment }\end{array}$} \\
\hline \multicolumn{7}{|c|}{ First NFL value per patient } \\
\hline No treatment & 119 & $20.3(2.9,1538.4)$ & 1.00 (reference) & $\mathrm{N} / \mathrm{A}$ & 1.00 (reference) & $\mathrm{N} / \mathrm{A}$ \\
\hline Treatment & 23 & $33.4(9.4,647.3)$ & $-0.24(-0.82,0.35)$ & 0.43 & $-0.25(-0.78,0.28)$ & 0.35 \\
\hline \multicolumn{7}{|c|}{ Final NFL value per patient } \\
\hline No treatment & 107 & $27.1(2.2,1538.4)$ & 1.00 (reference) & $\mathrm{N} / \mathrm{A}$ & 1.00 (reference) & $\mathrm{N} / \mathrm{A}$ \\
\hline Treatment & 35 & $40.0(3.1,1186.2)$ & $-0.01(-0.46,0.45)$ & 0.98 & $-0.02(-0.41,0.45)$ & 0.93 \\
\hline
\end{tabular}

$\mathrm{CI}=$ confidence interval. Regression coefficients, $95 \%$ CIs, and p-values result from linear regression models where NFL was the dependent variable. Regression coefficients are interpreted as the difference in mean NFL concentration (on the natural logarithm scale) between patients who had the given treatment and patients who did not have the given treatment. P-values $<0.0063$ were considered as statistically significant after applying a Bonferroni correction for multiple testing. 